\title{
A sorte deste mundo: percursos de Marilia de Dirceu no século XIX
}

\section{The fate of this world: paths of Marilia de Dirceu in the nineteenth century}

https://doi.org/10.34112/2317-0972a2018v36n72p73-83

\section{Joaci Pereira Furtado ${ }^{1}$}

RESUMO: Num dia incerto de fevereiro de 1810 desaparecia, na ilha de Moçambique, o magistrado, jurista e poeta Tomás Antônio Gonzaga. Nascido na cidade do Porto em 1744, tornou-se célebre por sua participação - suposta ou verdadeira, mas sempre negada por ele - na Inconfidência Mineira (1788-1789), posteriormente erigida como instante fundador da brasilidade pela história oficial. Mas ele figura sobretudo como autor, entre outras obras, de um dos mais difundidos livros escritos em língua portuguesa: Marília de Dirceu, conjunto de poemas líricos inicialmente publicado, em quatro edições acrescidas, de 1792 a 1802. As inúmeras edições desses versos, entretanto, nunca foram acompanhadas de certa investigação bibliográfica talvez elementar. É dela que este artigo trata.

Palavras-chave: Marília de Dirceu; edições; romantismo; arcadismo.

ABSTRACT: In an uncertain day of February 1810, the magistrate, jurist and poet Tomás Antônio Gonzaga disappeared in the island of Mozambique. Born in Porto in 1744, he had became famous for his participation - supposed or real, but always denied by him - in the "Inconfidência Mineira" or The Minas Conspiracy (1788-1789), later established as a founder instance of Brazilianness according to official history. He mainly figures, however, as the author, among other works, of one of the most widely known books written in Portuguese:

1. Universidade Federal Fluminense, Niterói, RJ, Brasil. 
Marilia de Dirceu, a set of lyrics first published in four changed editions, from 1792 to 1802 . The numerous editions of these verses, however, have never been object of bibliographic research, even elementary. This paper deals with that.

Keywords: Marilia de Dirceu; published editions; Classicism; Romanticism.

Da mais alta janela da minha casa

Com um lenço branco digo adeus Aos meus versos que partem para a Humanidade.

Quem sabe quem os terá? Quem sabe a que mãos irão?

Fernando Pessoa

Pedro Antônio Correia Garção, Domingos dos Reis Quita, Francisco José Freire, Antônio Ribeiro dos Santos, Antônio Dinis da Cruz e Silva, Nicolau Esteves Negrão, Luís José Correia de Amaral França, Manuel de Figueiredo, Nicolau Tolentino, Manuel Inácio da Silva Alvarenga, Pedro de Azevedo Tojal, Francisco de Melo Franco, José Agostinho de Macedo, Antônio Joaquim de Carvalho, Francisco de Paula de Figueiredo, João Robert du Fond, Alexandre Antônio de Lima, João Jorge de Carvalho, Francisco Manuel Gomes da Silveira Malhão, João Pedro do Monte, Anacleto da Silva Morais, José Basílio da Gama, Manuel Maria Barbosa l'Hedois du Bocage, José de Santa Rita Durão, Cláudio Manuel da Costa, Inácio José de Alvarenga Peixoto, Tomás Antônio Gonzaga. Não deve causar espanto se poucos - ou quiçá nenhum - desses nomes hoje signifique algo para a maioria dos falantes da língua portuguesa, assim mesmo menos pelo que escreveram do que pelo que fizeram: trata-se de uma de sociedade de poetas mortos para o leitor lusófono contemporâneo, que de alguns deles tem notícia certamente por causa da tríade que se envolveu - ou foi envolvida - na Inconfidência Mineira: Cláudio, Alvarenga Peixoto e Gonzaga. Ou pela fama dos versos obscenos de Bocage, ele mesmo um libertino hoje mais conhecido pelo anedotário envolvendo sua biografia do que pela leitura de sua poesia (que, aliás, não se limita ao obsceno). Ou então pelo eventual contato, em aulas de literatura no ensino fundamental ou médio, com fragmentos de obras como Caramuru, de Santa Rita Durão, O Uraguay, de Basílio da Gama, Vila Rica, de Cláudio, os versos "Bárbara bela,/ Do Norte estrela,/ Que o meu destino/Sabes guiar,/ De ti ausente,/ Triste somente/ As horas passo/ A suspirar", de Alvarenga, Marilia de Dirceu e Cartas 
chilenas, de Gonzaga. Não deveria ser de outro modo, por certo. Hoje alçada ao cânon inclusive daquilo que precedeu ou prenunciou a nacionalidade brasileira na literatura, essa poesia é ruína de uma sociedade organizada por valores políticos, religiosos e estéticos fundamentados no absolutismo católico, na hierarquia estamental e no engenho discursivo no manejo retórico de tropos e figuras segundo convenções de gosto que preconizavam, entre outras contensões, a metáfora clara, a verossimilhança, o decoro, o inutilia truncat (TEIXEIRA, 1999, p. 141-64). As sensibilidades de agora são outras, outras as religiões ou descrenças, outros os valores políticos e os paradigmas inclusive para definir o que é literatura - e, nesta, o que vale a pena ser lido, citado ou apenas mencionado. Restrita a especialistas cada vez mais escassos, a poesia dita "árcade" talvez espere, neste ainda tenro século XXI, não mais que não ser esquecida. Tem razão o poeta: "A sorte deste mundo é mal segura" (GONZAGA, 1996, p. 597).

Essa sentença melancólica contrasta com a trajetória de Marilia de Dirceu ao longo do século XIX e ainda em boa parte do XX. Conjunto de sessenta e cinco poemas líricos que emulam a tradição que remonta a Horácio e Virgílio, a obra foi publicada pela primeira vez em 1792, em Lisboa, com seu autor já no degredo em Moçambique pela participação na conspiração contra o domínio colonial português em Minas Gerais o que indica que sua condição de réu, desde 1789, não obliterou o contato, direto ou indireto, com seu editor em Portugal, ou não impediu que alguém encaminhasse os originais para publicação. Até 1805 o livro teria cinco edições - número bastante expressivo, para os padrões da época, ainda que apenas duas (a de 1799 e a de 1802) tragam o texto integral dividido em duas partes, e uma terceira edição, a de 1800 , com a terceira parte composta de 24 poemas, seja integralmente apócrifa (SILVA, 1967, p. 27). De qualquer modo, são essas edições que fundamentaram as que se sucederam até 1885 , totalizando, conforme um dos levantamentos, trinta e três, e configurando impressionante fenômeno editorial: Marilia de Dirceu foi ou teria sido a segunda obra literária escrita em língua portuguesa mais lida no século XIX, perdendo a primazia apenas para Luís Vaz de Camões e seu Os lusíadas, segundo Haroldo Paranhos (1937, p. 202).

Se esses números impressionam, alguns dados ampliam a notável extensão e rapidez do alcance desses versos de Gonzaga. A prática da leitura em voz alta, em grupo, numa sociedade com tão baixo letramento como a colonial ou a brasileira do século XIX, multiplicou o público das liras, que ganharam outra forma bastante ou ainda mais popular de difusão: provavelmente já no final do século XVIII elas receberam suas primeiras versões musicais, recolhidas por César das Neves no Cancioneiro de músicas populares, obra monumental publicada em três volumes, 
entre 1893 e 1898 , na cidade do Porto. São doze liras, todas da segunda parte do livro, compostas em anos diferentes e por autores anônimos, em sua maioria ao gosto da virada do Setecentos para o Oitocentos, como árias italianizantes - sendo que quatro delas parecem "encaminhar-se para um sentimentalismo de marca mais romântica” (EULÁLIO, 200o, [p. 8]). É plausível imaginar, ao longo do século XIX, saraus, jantares, reuniões familiares ou simples momentos de ócio pontuados por essas liras acompanhadas, conforme a hipótese da musicóloga Anna Maria Kieffer, preferencialmente pela viola - instrumento de enorme popularidade no mundo luso-colonial (KIEFFER; NOGUEIRA; GLOEDEN, 200o, p. 11-22).

Isso se deve também, em boa parte, à apropriação romântica tanto das liras de Gonzaga como da biografia do poeta, que ao longo do século XIX passam a se confundir. Uma sucessão de fatos e incógnitas da conspirata deixou entreaberta a janela da tragédia, na qual os leitores românticos se apressaram em debruçar, vislumbrando no poema - assim como nas Cartas chilenas - passos da paixão que levariam ao calvário do 21 de abril, onde o imolado, é óbvio, não foi Gonzaga. As reuniões secretas na calada da noite, a invocação da elástica ideia de liberdade - "essa palavra/ que o sonho humano alimenta: que não há ninguém que explique/ e ninguém que não entenda!" (MEIRELES, 1979, p. 75) -, as esperanças depositadas no país esboçado por alguns conjurados, a traição - motivadas por interesses mesquinhos - que decreta o infortúnio de todos, a fantasmagórica figura do embuçado, os lances ousados de certas prisões, a espionagem e a captura de Joaquim José da Silva Xavier no Rio de Janeiro, o conturbado processo das devassas, a misteriosa morte de Cláudio Manuel da Costa, o gesto vicarial de Tiradentes, o jogo teatral das sentenças, a brutal e espetacular execução do alferes, o sofrimento do degredo, a morte de Alvarenga Peixoto exilado de sua Bárbara Heliodora, o fim do idílio Gonzaga/Dirceu e Maria Joaquina/Marília - são apelos dramáticos aos quais, no século XIX, o romantismo cedeu para além de qualquer compromisso com evidências históricas, quando não a despeito delas.

O quadro a óleo - hoje desaparecido - de João Maximiano Mafra retratando Gonzaga na prisão, pintado em 1843, é bastante representativo das imagens que o romantismo fez brotar das liras do poeta (supostamente) inconfidente. Reconhecendo que o que retratara "fora todo ideado" (apud FRIEIRO, 1981, p. $\left.73^{2}\right)$, o próprio artista atesta a pureza de sua obra quanto ao que de fato ela não é: uma tentativa de reproduzir "exatamente" a aparência do escritor.

2. Uma reprodução precária do quadro encontra-se à página 65 . 
Eduardo Frieiro diz que Mafra pinta um Gonzaga pouco verossímil. Talvez para os critérios dele, mas não para os dos românticos: de camisa aberta no peito, botas de cano alto, o mesmo "perfil numismático de adolescente e a mesma expressão pensativa e melancólica de Lord Byron retratado por R[ichard] Westall” (FRIEIRO, 1981, p. 72). O quadro, cuja reprodução orna a edição Laemmert de 1845 do livro, contém referências explícitas às liras I e XX da segunda parte de Marilia de Dirceu, nas quais a persona lírica descreve o ambiente lúgubre e a triste rotina de sua cela. Mas o retratista carrega nas feições juvenis do poeta, mostrando-o "com 24 anos em vez de 48 anos" (BURTON, 1976, p. 305). Longos, negros e fartos cabelos derramam-se sobre seus ombros, apesar de o próprio Dirceu reconhecer, na lira IV da segunda parte, que "Já, já me vai, Marília, branquejando/ Loiro cabelo, que circula a testa;/ Este mesmo, que alveja, vai caindo,/ E pouco já me resta” (GONZAGA, 1996, p. 631).

$\mathrm{Na}$ realidade, Mafra nada mais fazia do que construir a imagem pictórica desse que talvez tenha sido o primeiro herói romântico brasileiro (ou luso-brasileiro) - sobre o qual não faltou até mesmo a lenda de um fim trágico, enlouquecido no exílio (SOUTHEY, 1846, p. 308). A biografia oitocentista de Gonzaga, portanto, é indissociável de suas liras - quando não tributária, mais exatamente, da leitura que o romantismo fez destas últimas. $O$ eterno cantor de Marília explica o inconfidente, do mesmo modo como seu desafortunado idílio com Maria Joaquina Doroteia de Seixas aquece a contemplação de seus versos pela sensibilidade romântica: como no quadro de Mafra, Gonzaga-Dirceu é prisioneiro de seu drama amoroso. ${ }^{3}$

Uma leitura sincrônica, porém, nos levaria a outra conclusão:

Adotando o amor como princípio "de conhecer", Gonzaga não apenas definia seu âmbito de norma moral. Igualmente, transpondo para a individualidade subjetiva o fundamento do pensamento jusnaturalista, nosso autor nega as bases objetivas, verificáveis de um pensamento que busca alçar-se à condição de ciência. Por fim, o princípio do amor conflita ainda com as vertentes mais racionalistas no âmbito do direito natural "como se houvesse deliberado intuito de rebaixar a razão, entidade toda-poderosa do século de Gonzaga, para em seu lugar entronizar um sentimento, raiz da paixão”. (POLITO, 2006, p. 110).

3. Este parágrafo e os três anteriores foram adaptados de FURTADO, 1997, p. 100-3. 
Em termos menos obscuros: se admitirmos que, antes do século XIX, a constituição de qualquer discurso compreendia um complexo sistema de normas, recursos, referências e modos de organização das ideias adequados a determinados fins certamente as liras Marília de Dirceu nos soariam menos familiares - isto é, mais irredutíveis a pares de opostos como conservador/progressista, erudito/popular, sagrado/profano, democracia/autoritarismo, licenciosidade/repressão, público/ privado, preconceito/tolerância, realidade/ficção. É exatamente essa restituição arqueológica do texto às práticas discursivas de seu tempo que nos permitiria perceber, enfim, que o poema atribuído a Gonzaga é um artefato retórico. Nisto a fortuna foi mais generosa conosco do que com os arqueólogos que perscrutam cacos, não só porque há uma quantidade razoável de poemas semelhantes a Marília de Dirceu e contemporâneos dele, mas principalmente porque as preceptivas que orientavam sua confecção também nos são acessíveis.

Como sabemos, a retórica foi sistematizada na Antiguidade greco-latina em obras sobretudo de Aristóteles, Cícero e Quintiliano, constituindo objeto de apropriações até conflitantes ao longo das idades Média e Moderna, mas permanecendo como a fronteira dentro da qual circulava a composição dos discursos. Na segunda metade do século XVIII luso-colonial o tom das preceptivas retórico-poéticas é definido por Ignacio Luzán, Nicolas Boileau, Ludovico Muratori, Gian Vincenzo Gravina, Cândido Lusitano e Luís Antônio Verney, evidenciando, segundo João Adolfo Hansen, que na poesia árcade a "mímesis é aristotélica, feita como pintura não da suposta realidade empírica, mas da realidade de tópicas discursivas" (HANSEN, 1997, p. 18). Assim, ao contrário do que diz sua tradição recepcional, Marília de Dirceu não retrata a subjetividade de um homem apaixonado por uma mulher, mas soma lugares-comuns à estilização do ideal coevo de amor.

Além de transcender a literatura, Marilia de Dirceu logo excedeu os limites da língua. Em 1825, saía em Paris a edição francesa, com tradução (em prosa) de Eugène de Monglave e Prosper Chalas, pela editora de Charles-Louis-Fleury Panckoucke. A tradução italiana, por Giovenale Veggezzi-Ruscalla, publicada em Turim pela Stamperia Sociale degli Artisti, é de 1844. Em 1868, Marilia de Dirceu ganhava tradução para o latim por Antônio de Castro Lopes, editada no Rio de Janeiro pela Tipografia Quirino \& Irmãos. Além disso, dois fragmentos do livro apareceram em antologias no exterior: a lira XV da segunda parte, "Eu, Marília, não sou algum vaqueiro", recriada em alemão por Ferdinand Schmid e impressa em Berlim, em 1879, pela editora de Gebrüder Paetel; e, embora publicada postumamente, a tradução - ou "paráfrase", como prefere 
Boris Schnaiderman (1978, p. 37) - para o russo da lira IX da segunda parte, "A estas horas", que é de 1825 e pertence a ninguém menos que Alexander Sergueievitch Pushkin, que pode ter conferido a Gonzaga o privilégio de ser o primeiro poeta de língua portuguesa a ser vertido - ainda que do francês (SCHNAIDERMAN, 1978, p. 37) - para o idioma de Tolstói e Dostoiévski (SILVA, 1967, p. 32).

Embora já no século XX, mas num caso talvez único no Brasil, em que personagem de obra literária nomeia município, cabe lembrar que a cidade paulista de Marília deve seu nome ao agora célebre livro de Tomás Antônio Gonzaga: Adolfo Augusto Pinto, chefe do Escritório Central da Companhia Paulista de Estradas de Ferro, seguindo a ordem alfabética das estações criadas a partir de Piratininga, ao levar o ramal ferroviário até o distrito de Paz optou por batizar a estação local como "Marília" porque, durante então recente viagem à Europa, ao procurar um livro na biblioteca do navio Giulio Cesare, logo encontrou um exemplar de Marília de Dirceu (PÓVOAS, 1947, p. 27). O município surgiu oficialmente com esse nome por lei estadual de 22 de dezembro de 1926.

A trajetória do livro, porém, ainda guarda lacunas, imprecisões, divergências e mistérios que novas pesquisas podem solucionar ou minimizar. Conforme dito acima, não se sabe como os manuscritos de Gonzaga chegaram à Tipografia Nunesiana. Nem mesmo a mais bem documentada biografia do poeta, que inclusive esclarece passagens até então pouco ou nada conhecidas de sua vida, explica como o réu conjurado e depois degredado em Moçambique conseguiu editar seu único livro impresso em vida, cujo lançamento foi noticiado pela Gazeta de Lisboa em 10 de novembro de 1792 (GONÇALVES, 1999, p. 373-4). Entre os que escreveram sobre a bibliografia de Marília de Dirceu, porém, não há consenso sobre o número de edições do livro ao longo do século XIX. Domingos Carvalho da Silva, o mais recente estudioso a se ocupar da matéria, computa trinta e cinco até 1967 (SILVA, 1967, p. 32), enquanto Haroldo Paranhos, como mencionado, identifica trinta e três apenas entre 1792 e 1885. Já Emanuel Eduardo Gaudie Ley, em sua "Gonzagueana da Biblioteca Nacional”, registrava, até 1928, vinte e cinco (LEY, 1927, p. 449). Sobre a bibliografia de Marilia de Dirceu também escreveram, ao longo do século XIX e nas primeiras quatro décadas do XX, Francisco Adolfo de Vanhargen, Teófilo Braga, Joaquim Norberto, Sacramento Blacke, Ricardo Pinto de Matos, Alfredo do Vale Cabral, Teixeira de Melo, José Veríssimo, Tancredo de Barros Paiva, Artur Mota, Oswaldo M. B. de Oliveira e Simões dos Reis - lista expressiva em quantidade e qualidade, que demonstra o interesse que a obra despertava entre os eruditos. 
Por razões diversas, porém, o número de edições encontradas ou supostas por eles oscila entre os cautelosos vinte e cinco de Gaudie Ley e os improváveis sessenta e nove - até 1934 - de Simões dos Reis (LEY, 1927, p. 424-5). Além de possíveis problemas de acesso à informação, ou de ausência de rigor no trato com as fontes, há certos aspectos técnicos - como, por exemplo, não considerar como nova edição a íntegra de Marília de Dirceu inserida nas duas versões das Obras completas de Tomás Antônio Gonzaga organizadas por Rodrigues Lapa (SILVA, 1967, p. 34) - e uma questão de fundo teórico, menos ou mais explícita, orientando os critérios para a contagem das edições: o conceito de "autoria" e seu pressuposto romântico-burguês, a "originalidade", "mercadoria inventada no século XIX" que, no mercado da livre concorrência e da competição, remunera o detentor dos direitos autorais (HANSEN, 2013, p. 18). Gonzaga, ou o que quer que se atribua a ele, está muito mais próximo das práticas letradas dos séculos anteriores que às do XIX em cujo alvorecer morreu. Se assim é, não cabe esperar "genuidade" das primeiras edições dessa poesia, da mesma forma que ela é improcedente quando se trata das letras ditas "medievais" e "renascentistas" dos séculos XII a XVII (HANSEN; MOREIRA, 2013, p. 37). "Autor”, no mundo historicamente contemporâneo de Gonzaga, é muito mais tributário da noção latina de auctoritas - isto é, "autoridade" - do que do conceito romântico de expressão de uma subjetividade ou psiqué. Até o surgimento do romantismo, a ficção pressupunha "a mímesis aristotélica e a doutrina latina da imitatio como regramento de gêneros. Cícero não era propriamente o nome de um indivíduo [...], mas a classificação da oratória, assim como Virgílio significava 'epopeia”' (HANSEN, 2013, p. 18). Desse ponto de vista, ganha outro significado e especial interesse a edição apócrifa de 1800, renegada como "oportunista" por todos os bibliógrafos de Marilia de Dirceu: Gonzaga tornou-se sinônimo de "lírica" - ou, no mínimo, de certa lírica. Assim como, na fixação do texto, talvez seja tarefa impossível chegar à "última intensão do autor" a partir das edições que lhe foram contemporâneas em vida, já que há variantes entre todas elas pelo menos até 1811 . Quando a crítica textual e a ecdótica se descentram do autor, as próprias variantes ganham relevância, pois "as várias versões concorrentes da obra postas em circulação foram objeto de recepção" e, portanto, interessam à história da leitura. Em suma, "autoria" não é critério de autorização e legibilidade (HANSEN; MOREIRA, 2013, p. 38-9). Também para a bibliografia pode não importar, pois, se Gonzaga efetivamente escreveu a terceira parte de Marilia de Dirceu e emendou as duas primeiras nas edições que se sucederam de 1792 até sua morte, num dia incerto de fevereiro de 1810, em Moçambique. 
A adoção explícita de semelhante paradigma, assim como a do critério que inclua a inserção do conjunto das liras gonzaguianas nos volumes de sua obra completa ou de outras obras, como é o caso de A poesia dos inconfidentes (PROENÇA FILHO, 1996, p. 571-708), pode reconfigurar a contagem das edições do livro ao longo do século XIX - e do XX, que ainda permanece inacabada. Hoje, a digitalização dos catálogos e dos acervos, acessível pela internet, facilita bastante a tarefa de verificação da existência e da descrição física das edições, mas em boa parte dos casos certamente será indispensável o manuseio dos exemplares a fim de se comprovar suas características e evitar confusões. É imprescindível checar, edição a edição, além do ano, da cidade e do editor, quais as liras impressas e a sequência delas no interior das partes e do volume e designar a coleção ou a série a que por ventura ele pertença, saber distinguir edição de simples reimpressão (esta, sem valor para o levantamento), identificar a natureza e a gramatura do papel, assim como a tipologia gráfica empregada, medir as dimensões do volume (altura, largura e profundidade) e pesá-lo, registrar a presença e a autoria de vinhetas e ilustrações, detectar o colofão e seu texto, descobrir (se possível) a tiragem e a numeração do exemplar, descrever a encadernação, apontar a presença de frontispício ou folha de rosto e a autoria de eventuais aparatos editoriais (como nota do editor, nota biográfica, sumário, prefácio, posfácio, notas de rodapé ou de fim de volume, índice remissivo de títulos e/ou primeiro verso, glossário, cronologia, bibliografia ou textos de orelha e contracapa), relatar possível sobrecapa (ou "jaqueta") e sua configuração, contar o número efetivo de páginas impressas (separando as numeradas com algarismos romanos ou não numeradas das paginadas com arábicos), indicar a existência de fitilho marcador de página (e seu material) e de página de créditos. Somente uma investigação rigorosa, atenta a todas às minúcias, poderá elidir as controvérsias que a bibliografia de Marília de Dirceu mais acumulou que resolveu, nos últimos duzentos anos. Além disso, e sobretudo, semelhante pesquisa colocará à prova a impactante afirmação de Haroldo Paranhos, repetida por outros historiadores mas cujas provas nunca foram apresentadas: a de que os versos de Gonzaga perdem apenas para Os lusíadas, em número de edições, ao longo do século XIX. Para sustentar semelhante assertiva, é preciso, além de ter absoluta segurança sobre as edições da lírica gonzaguiana, realizar ou acessar consistente levantamento das edições do épico camoniano no Oitocentos. Ainda assim, restaria verificar se, naquele século, não houve outra obra poética originalmente escrita em português mais editada que Os lusíadas. Para quem gosta de enigmas, eis aí um, bastante desafiador. 
Seja como for, não resta dúvida quanto ao êxito editorial das liras gonzaguianas, nos duzentos anos que se seguiram à sua primeira edição, e quanto à importância dessa obra, alçando seu autor ao topo do cânon da literatura de língua portuguesa - por mais que hoje se faça menos caso de seus versos que de seu autor. Se agora Marília de Dirceu já não desperta a mesma paixão - o que provavelmente se constatará pelo decréscimo do número de edições ao longo século $\mathrm{XX}$-, valerá a pena investigar as causas daquele arrebatamento de antanho que neste século XXI pode soar estranho, se não até ingênuo. Quem sabe nesse estranhamento reconheçamos, afinal, um pouco do que somos.

\section{REFERÊNCIAS}

BURTON, Richard F. Viagem do Rio de Janeiro a Morro Velho. Tradução de David Jardim Jr. Belo Horizonte: Itatiaia, 1976.

EULÁLIO, Alexandre. Apresentação da $1^{a}$ edição do disco. In: KIEFFER, Anna Maria; NOGUEIRA, Gisela; GLOEDEN, Edelton. Marília de Dirceu. São Paulo: Akron, 2000. p. 5-8.

FRIEIRO, Eduardo. O diabo na livraria do cônego. Belo Horizonte: Itatiaia, 1981.

FURTADO, Joaci Pereira. Uma república de leitores: história e memória na recepção das Cartas chilenas (1845-1989). São Paulo: Hucitec, 1997.

GONÇALVES, Adelto. Gonzaga, um poeta do iluminismo. Rio de Janeiro: Nova Fronteira, 1999.

GONZAGA, Tomás Antônio. Marília de Dirceu. In: PROENÇA FILHO, Domício (Org.). A poesia dos inconfidentes. Rio de Janeiro, Nova Aguilar, 1996, p. 571-708.

HANSEN, João Adolfo. Prefácio. In: FURTADO, Joaci Pereira. Uma repúlica de leitores: história e memória na recepção das Cartas chilenas (1845-1989). São Paulo: Hucitec, 1997, p. 11-20.

HANSEN, João Adolfo. O que é um livro? São Paulo: SESCP, 2013.

HANSEN, João Adolfo; MOREIRA, Marcello. Para que todos entendais: poesia atribuída a Gregório de Matos e Guerra - Letrados, manuscritura, retórica, autoria, obra e público na Bahia dos séculos XVII e XVIII. Belo Horizonte: Autêntica, 2013.

KIEFFER, Anna Maria; NOGUEIRA, Gisela; GLOEDEN, Edelton. Recriando as doze árias de Marília de Dirceu. In: . Marília de Dirceu. São Paulo: Akron, 2000. p. 10-21.

LEY, Emanuel Eduardo Gaudie. Gonzagueana da Biblioteca Nacional. Anais da Biblioteca Nacional, Rio de Janeiro, n. 49, p. 417-92, 1927.

MEIRELES, Cecilia. Romanceiro da Inconfidência. 4. ed. Rio de Janeiro: Civilização Brasileira, 1979. PARANHOS, Haroldo. História do romantismo no Brasil. São Paulo: Cultura Brasileira, 1937, v. 1.

POLITO, Ronald. Um coração maior que o mundo: Tomás Antônio Gonzaga e o mundo lusocolonial. São Paulo: Globo, 2006.

PÓVOAS, Glicério. Marília. Marília: Serviço de Estatística da Prefeitura, 1947.

PROENÇA FILHO, Domício (Org.). A poesia dos inconfidentes. Rio de Janeiro: Nova Aguilar, 1996. 
SCHNAIDERMAN, Boris. Pushkin, tradutor de Gonzaga. In: . Projeções: Rúsia/Brasil/

Itália. São Paulo: Perspectiva, 1978. p. 37-41.

SILVA, Domingos Carvalho da. Edições brasileiras de Marília de Dirceu. s/l, s/e, 1967, p. 27-32.

SOUTHEY, Robert. Conspiração em Minas Geraes no anno de 1788. Revista Trimensal de Historia e Geographia, Rio de Janeiro, n. 8, p. 297-311, jul-set 1846.

TEIXEIRA, Ivan. Mecenato pombalino e poesia neoclássica: Basílio da Gama e a poética do encômio. São Paulo: Edusp, 1999.

\section{SOBRE O AUTOR}

Joaci Pereira Furtado é graduado em História (Universidade Federal de Ouro Preto) e é mestre e doutor em História Social (Universidade de São Paulo). É professor do Departamento de Ciência da Informação da Universidade Federal Fluminense, e autor de Uma república de leitores (Hucitec) e organizador da edição das Cartas chilenas, de Tomás Antônio Gonzaga, publicada pela Companhia das Letras. Atualmente desenvolve o projeto Museu Virtual da Leitura, canal do Youtube que recolhe depoimentos de leitores, e pesquisa as práticas de leitura entre graduandos da Universidade Federal Fluminense.

E-mail: joacifurtado@id.uff.br.

Recebido em 19 de janeiro de 2018 e aprovado em o8 de março de 2018. 